\title{
DEMOCRACIA, DESIGUALDADES E CORRUPÇAO: UMA ANÁLISE DA QUALIDADE DEMOCRÁTICA NA AMÉRICA LATINA. ${ }^{1}$ DEMOCRACY, INEQUALITY AND CORRUPTION: AN ANALYSIS OF THE DEMOCRATIC QUALITY IN LATIN AMERICA.
}

Maria Salete Souza de Amorim*

RESUMO: O debate sobre a democracia e a qualidade da democracia se ampliou nos últimos anos, tendo em vista que a maioria dos países do mundo adotou o regime democrático. Dada a relevância do tema, o artigo visa contribuir com as reflexões e estudos sobre a qualidade da democracia na América Latina, uma região que enfrenta uma série de problemas e desafios de cunho político, econômico e social em sua recente experiência democrática. Através de uma análise descritiva de dados, busca-se analisar indicadores de qualidade da democracia, indicadores socioeconômicos e percepção da corrupção, referentes aos países do Mercosul, de modo a estabelecer relações entre a realidade da democracia latinoamericana e a literatura corrente. Foi possível observar que a despeito da consolidação de procedimentos democráticos, as democracias se caracterizam como híbridas, convivendo com altos níveis de desigualdades e de corrupção política.

Palavras-chave: América Latina; qualidade da democracia; indicadores econômicos; desigualdade; corrupção.

\footnotetext{
${ }^{1}$ Este artigo é uma versão revisada e ampliada do paper apresentado no $\mathrm{IV}^{\mathrm{o}}$ Encontro Internacional de Ciências Sociais (EICS), Pelotas (RS), Brasil, 2014.

* Doutora em Ciência Política pela Universidade Federal do Rio Grande do Sul (UFRGS); Professora do Programa de Pós-Graduação em Ciências Sociais da Universidade Federal da Bahia (UFBA) e vice-coordenadora do Núcleo de Estudos Ambientais e Rurais da Universidade Federal da Bahia (NUCLEAR/UFBA), Salvador (BA), Brasil; E-mail: saleteamorim@uol.com.br
} 
ABSTRACT: The debate on democracy and its quality have expanded in recent years, since most of the world countries have adopted democratic regime. Given the importance of this topic, this article aims to contribute to the discussions and studies on the quality of democracy in Latin America, a region which faces a set of political, economic and social problems and challenges in its recent democratic experience. Through a descriptive analysis of data, the aim is to analyze democracy quality indicators, socio-economic indicators and perception of corruption related to Mercosur countries, so as to establish relations between Latin American democracy reality and the current literature. It was observed that despite the consolidation of democratic procedures, democracies are characterized as hybrid, in which high levels of inequality and political corruption are present.

Keywords: Latin America; quality of democracy; economic indicators; inequality; corruption.

\section{INTRODUÇÃO}

O debate sobre a qualidade da democracia se ampliou nos últimos anos, diante do fato de que a maioria dos países do mundo adotou o regime democrático. As abordagens sobre as definições de democracia e de qualidade da democracia apresentam diferentes enfoques acerca da forma, conteúdos e resultados da democracia, mas quanto à classificação dos países, observa-se a existência de um fio condutor comum, associado aos aspectos procedimental e processual. Do ponto de vista institucional, é possível estabelecer parâmetros de comparação entre os países, em seus diferentes contextos sócio-políticos, situando-os numa escala de gradação entre "mais" ou "menos" democráticos. Recentemente, alguns institutos de pesquisa têm incluído variáveis de cunho mais substantivo, referente aos aspectos econômicos, sociais e culturais das democracias.

A democracia tornou-se, nas sociedades contemporâneas, um valor universal, e tem sido considerada a melhor forma de governo. Problematizando as concepções de democracia, constata-se uma dis- 
tância entre os ideais democráticos e a democracia real, cabendo ao cidadão, na prática do exercício democrático, o restrito papel de eleitor. De forma geral, teóricos e cidadãos atribuem significados distintos para a democracia e do ponto de vista de seu funcionamento, são apontadas muitas críticas, especialmente no âmbito do desempenho institucional, econômico e social.

Pontualmente, no contexto da América Latina, a democracia vivencia momentos de estabilidade, associados à ocorrência de processos eleitorais, à existência de instituições democráticas e às garantias legais de liberdade e igualdade política. Mas vivencia também momentos de instabilidades vinculados a crises políticas e econômicas, em que os escândalos de corrupção, as taxas de pobreza e as desigualdades são os principais propulsores.

Dada a relevância do tema, o artigo visa contribuir com os estudos sobre a democracia e a qualidade da democracia na América Latina, tendo em vista analisar indicadores de qualidade democrática, indicadores socioeconômicos e a percepção da corrupção, relativos aos países do Mercado Comum do Sul (Mercosul), de modo a estabelecer relações entre a realidade da democracia latinoamericana e a literatura corrente. O período selecionado é de 2010 a 2013, devido a disponibilidade dos indicadores para os cinco países (Uruguai, Argentina, Brasil, Paraguai e Venezuela), nestes três anos consecutivos. Os dados econômicos são concernentes aos levantamentos realizados pela Comissão Econômica para a América Latina (CEPAL) e pelo Socio-Economic Database for Latin America and the Caribbean (SEDLAC). Utilizam-se também dados de dois institutos de pesquisa: Democracy Ranking Association que mensura a qualidade da democracia a partir de características do sistema político e do desempenho das seguintes dimensões: economia, educação, saúde, meio ambiente, e gênero; e os dados do portal da Transparency Internacional, the gobal anti-corruption organisation, que classifica os países a partir das percepções da corrupção no setor público, cujo índice é elaborado com base em informações recolhidas por uma variedade de instituições respeitáveis.

$\mathrm{O}$ artigo está estruturado em três seções. Na primeira seção 
discutem-se as definições de democracia na literatura pertinente ao tema, dentro dos limites do escopo deste artigo. Na segunda seção analisam-se as recentes discussões sobre a qualidade da democracia. E na terceira seção se estabelece comparações entre os indicadores de qualidade da democracia, os indicadores socioeconômicos, e os de percepção da corrupção, analisando aspectos comuns e os desafios das democracias dos países do Mercosul.

\section{DISCUTINDO AS CONCEPÇÕES DE DEMOCRACIA}

A concepção clássica de democracia, com base nos princípios da igualdade entre os cidadãos, de liberdade e respeito a lei, adotou vários métodos de seleção dos governantes, tendo em vista "preservar a responsabilidade de prestação de contas dos administradores políticos e do sistema estatal de modo mais geral, inclusive a rotatividade de tarefas, o sorteio e a eleição direta" (Held, 1987, p. 21). A concepção contemporânea de democracia manteve o pressuposto da igualdade entre os cidadãos e do direito à participação política, dando ênfase ao processo eleitoral para a escolha de representantes.

Uma das definições de democracia mais predominantes, na área da Ciência Política, é aquela que caracteriza a democracia a partir da existência de regras e procedimentos que definirá quem está autorizado a tomar as decisões coletivas. A teoria democrática proposta por Joseph Schumpeter (1984), influenciada pelas teorias elitistas ${ }^{2}$, especialmente, pelas teorias weberianas sobre o papel central da burocracia e da racionalidade no contexto da modernização capitalista, constitui um marco importante no debate sobre a democracia contemporânea.

Entre os aspectos presentes nas modernas democracias liberais do século XX, o autor destaca a luta competitiva entre os partidos políticos de massa pelo poder, e o importante papel das lideranças políticas que buscam apoio e voto, usando novas técnicas de propaganda e convencimento. Em sua obra Capitalismo, Socialismo e Democracia, publicada em 1942, Schumpeter argumenta que o modelo de democracia possível no mundo contemporâneo é aquele em que o governo é

${ }^{2}$ Gaetano Mosca; Robert Michels; Vilfredo Pareto; Max Weber. 
eleito pelo povo para tomar as decisões políticas, enfatizando, portanto, que a competição eleitoral ocorre entre as elites políticas.

O referido autor propõe uma concepção de democracia mais pragmática e funcional, pautada numa realidade de mercados competitivos e na expansão da lógica econômica para outras esferas da sociedade. Define democracia como um método político, um "arranjo institucional para se alcançarem decisões políticas - legislativas e administrativas" (Schumpeter, 1984, p. 304). Ao afirmar que o cidadão comum não possui discernimento ou conhecimento sobre as questões políticas, o autor conclui que a função primária do eleitorado é votar em lideranças capacitadas e racionais, que estão em livre competição no mercado político dos votos. Note-se que esta concepção de democracia é bastante usual nos meios acadêmicos, políticos e sociais.

Essa corrente teórica ganhou inúmeros adeptos, entre eles Anthony Downs (1999), Norberto Bobbio (2000), Giovanni Sartori (1994). Suas obras reforçam os argumentos do elitismo democrático acerca da dimensão vertical da democracia, da importância do aspecto procedimental de competição eleitoral entre as elites, da existência de instituições democráticas para o funcionamento do método, bem como a aceitação das regras do jogo e de seus resultados.

As contribuições do elitismo democrático e dos pressupostos da racionalidade e da teoria econômica foram fundamentais na definição de democracia cunhada por Anthony Downs. Em sua obra Uma teoria econômica da democracia, originalmente publicada em 1957, o autor argumenta que o objetivo central de uma democracia é selecionar um governo por meio das eleições, e, por conseguinte o governo eleito buscará maximizar o apoio político visando sua eleição/reeleição. Segundo o modelo de Downs (1999), os eleitores e as elites políticas agem racionalmente, e suas ações se aproximam da lógica econômica do mercado: os partidos maximizem seus votos (lucros), enquanto os eleitores procuram maximizar suas vantagens (utilidades). A definição econômica da democracia pressupõe que os indivíduos se movem em direção a suas metas, visando alcançá-las com o mínimo de recursos e o máximo de aproveitamento. Neste caso, a lógica é de que o governo planeja suas políticas visando res- 
ponder às expectativas dos eleitores e obter o máximo de votos, e por sua vez, o cidadão tenderá a escolher o candidato que ele acredita que lhe proporcionará mais benefícios.

Baseando-se nos parâmetros da definição mínima de democracia, Norberto Bobbio a define como um conjunto de regras e procedimentos de seleção de lideranças políticas através das eleições. Por este processo será deliberado quem está autorizado a tomar as decisões coletivas. $\mathrm{O}$ autor argumenta que a relação entre racionalidade e democracia é um ideal-limite, pois na prática "falta à grande maioria dos indivíduos os conhecimentos necessários para construir um juízo pessoal e fundamentado diante das decisões que deve tomar" (Bobbio, 2000, p. 425). A regra da maioria seria apenas um dos elementos para o bom funcionamento da democracia, e tem sua expressão maior no sufrágio universal, onde a partir de um expediente técnico (contagem dos votos) define-se quem e quantos tomarão as decisões políticas. A maioria pressupõe a existência de uma minoria, que pode estar sendo alijada do processo, argumenta Munck (2012). Mas pela lógica desta abordagem, ainda assim teremos uma democracia, não necessariamente com qualidade.

Numa perspectiva mais processual, Robert Dahl (1997, p. 25) parte do pressuposto de que a "característica-chave da democracia é a contínua responsividade do governo às preferências de seus cidadãos, considerados politicamente iguais". Esta condição de igualdade política implica no direito de todo e qualquer cidadão formular, expressar e ter preferências igualmente consideradas na conduta do governo. $\mathrm{O}$ autor argumenta que a igualdade política (um homem, um voto), a cidadania inclusiva, a liberdade de expressão, e as fontes de informações diversificadas, são algumas das exigências mínimas para um país democrático.

Nesta perspectiva, o referido autor argumenta que "as poliaquias podem ser pensadas então como regimes relativamente (mas incompletamente) democratizados, ou, em outros termos, as poliarquias são regimes que foram substancialmente popularizados e liberalizados, isto é, fortemente inclusivos e amplamente abertos à contestação pública" (Dahl, 1997, p. 31). Em contraposição, alguns autores alegam que, na prática, as desigualdades socioeconômicas e 
culturais entre os grupos sociais dificultam o acesso aos recursos e à competição política, mantendo a exclusão de alguns grupos (Held, 1987). Quanto à desigualdade econômica, Dahl admite que se ela se mostrar persistente, pode constituir em um obstáculo para o alcance de um nível satisfatório de igualdade política, uma vez que aqueles que detêm maior volume de recursos tendem a usá-lo para exercer influência no sistema político em proveito próprio.

Buscando traçar um prognóstico sobre o futuro dos regimes democráticos, a literatura considera que houve avanços significativos nos últimos anos, mas pondera que muitas promessas da democracia não foram cumpridas. Constata que há uma distância entre o modelo ideal e real de democracia e de sociedade democrática e pluralista. Ao invés de cidadania ativa e exercício da prática democrática, denota-se um afastamento dos cidadãos da esfera da política em detrimento da permanência de práticas antidemocráticas como o clientelismo, nepotismo, favoritismo, e corrupção.

Dessa forma, quando se pretende aprofundar o sentido da democracia, busca-se observar o desempenho institucional, as formas de participação existentes, as garantias das liberdades civis, o respeito às leis, a existência de fontes alternativas de informação, e principalmente avalia-se a percepção dos cidadãos sobre a democracia, sobre a corrupção, sobre a capacidade de resposta dos governos às demandas sociais, sobre a existência de agências de controle e fiscalização autônomas e independentes.

Portanto, define-se democracia como um sistema político que assegura liberdades políticas e civis e igualdades política, econômica e social. Ao mesmo tempo em que garanta mecanismos de accountability vertical, horizontal e social, tendo em vista a transparência e a responsividade dos governos democráticos. A concepção de democracia adotada neste trabalho está relacionada à vertente substantiva, aquela que analisa os conteúdos e os resultados da democracia, observando até que ponto o regime político promove o bem-estar da população e assegura, de fato, os ideais de liberdade e igualdade política e social (Barreda, 2012; Baquero, 2012; Diamond, Morlino, 2004; Moisés, 2010b; Munck, 2012; O'donnell, 2013). Obtêm-se 
uma avaliação muito mais completa da democracia, na perspectiva de contribuir com a análise da qualidade da democracia, seja através da proposição acerca de novos comportamentos políticos ou de conteúdos e resultados de políticas mais eficientes. É dentro desta abordagem que se insere a discussão sobre a qualidade da democracia, que será analisada na seção a seguir.

\section{DISCUTINDO AS CONCEPÇÕES DE QUALIDADE DA DE- MOCRACIA}

A agenda de pesquisa sobre a qualidade da democracia, especialmente no campo da pesquisa comparada, ao estabelecer uma distinção entre democracia ideal e democracia real, traz à tona aspectos formais e substantivos do regime democrático, problematizando o exercício da democracia nos diferentes países. A discussão sobre qualidade da democracia postula uma definição mais ampla de democracia, que incorpora os elementos normativos e procedimentais, mas enfatiza, sobretudo, os aspectos substantivos da democracia, que implicam numa avaliação permanente da efetividade da prática democrática.

No caso das democracias representativas, as instituições democráticas e os mecanismos de accountability vertical e horizontal, segundo O'Donnell (1998), são os principais fatores de análise da qualidade da democracia no tocante aos procedimentos. As eleições têm um importante papel no controle dos líderes políticos, especialmente pela oportunidade que o eleitor tem de avaliar o desempenho dos políticos e de votar ou não no candidato ao cargo público, punindo-o ou recompensando-o. A questão que se coloca é se o eleitor, em geral, tem informação suficiente para exercitar tal ponderação. Outra forma de controle social é a chamada accountability horizontal, que se refere a instituições ou atores coletivos que tem o poder de controlar o comportamento dos governantes. Em vários casos, esse monitoramento é exercido pelo parlamento, pelos tribunais constitucionais, e pelos órgãos de auditoria. Ao incorporar na análise a accountability social, exercida através da intervenção de diferentes grupos da sociedade civil, a perspectiva da definição de democracia 
se amplia, considerando dimensões que avaliam a efetividade dos direitos e a capacidade de resposta dos governos.

Quando a qualidade da democracia é avaliada a partir dos procedimentos e não dos resultados, parte-se do pressuposto de que onde ocorrem eleições limpas e justas, onde há participação eleitoral, onde os eleitos respondem as demandas sociais através de políticas, e onde existem mecanismos de prestação de contas, a qualidade da democracia será alta, mesmo que os resultados da gestão política não tenham resolvido problemas sociais e garantido direitos civis. $\mathrm{Na}$ análise de Levine e Molina (2012), essa seria uma avaliação de governança e não de qualidade da democracia.

Numa outra perspectiva, Barreda (2012) e Munck (2012) destacam três importantes fatores explicativos para a qualidade da democracia: 1) fatores estruturais; 2) fatores institucionais; 3) fatores culturais. Todos os fatores, em seu conjunto, contribuem para avaliar o desempenho das democracias, mas abordá-los isoladamente pode tornar os argumentos limitados e frágeis. A importância dos fatores estruturais consiste em levar em consideração o desenvolvimento econômico de um país, seu grau de modernidade e a oferta de serviços básicos de qualidade. Entretanto, crescimento econômico associado à desigualdade afeta negativamente a qualidade da democracia. Por sua vez, os fatores institucionais requerem a presença de um sistema partidário institucionalizado, insulado de práticas antidemocráticas como o clientelismo, nepotismo e corrupção, que afetam negativamente a qualidade da democracia, bem como de um sistema eleitoral que permita a realização de eleições periódicas, limpas e justas no país. A importância dos fatores culturais na avaliação na qualidade da democracia diz respeito às atitudes e comportamentos que os cidadãos têm em relação à política, e pesquisas indicam que comportamentos mais democráticos como a cooperação, o associativismo e a confiança interpessoal contribuem para elevar a qualidade democrática de um país.

Da mesma forma, para Diamond e Morlino (2004), a mensuração da qualidade da democracia exige avaliar a qualidade não apenas dos procedimentos, mas dos conteúdos e dos resultados do processo democrático. Há um destaque, sem dúvida, para o papel 
das eleições e do processo eleitoral, através dos quais se dá o acesso aos cargos públicos, e pelos quais se avaliam a estabilidade e a durabilidade do regime nos países estudados. Portanto, na avaliação dos procedimentos, verifica-se a lisura do processo eleitoral, a periodicidade das eleições, e o quão competitivo elas são. Verifica-se ainda a existência de organizações partidárias, de fontes alternativas de informação, e mecanismos de monitoramento sobre a eficácia das leis e das decisões governamentais. No que diz respeito à avaliação do conteúdo, é fundamental avaliar se os direitos e as liberdades estão garantidos nas políticas. Da mesma forma, os resultados da democracia devem ser avaliados através da capacidade de resposta (outputs) do sistema político às demandas da sociedade.

Em outro trabalho, Morlino (2010) argumenta que a qualidade da democracia possui duas dimensões importantes, associadas entre si, que diz respeito à dimensão dos procedimentos e à dimensão substantiva da democracia. O autor chama a atenção para a existência do Estado de direito e de um judiciário independente como condição para assegurar o respeito às leis, às liberdades civis, e à igualdade política. Assim como, destaca a importância dos aspectos culturais, dos valores e crenças dos cidadãos em relação à avaliação da qualidade da democracia. Neste caso, é pertinente a questão trazida por Putnan (2002), em seu estudo sobre o desempenho institucional da democracia italiana: a qualidade da democracia depende da qualidade de seus cidadãos? O autor parte do pressuposto de que onde há participação cívica, redes de associativismo e de cooperação, a democracia é mais efetiva.

Na mesma linha de argumentação, Inglehart e Wenzel (2009), partem da premissa de que o desenvolvimento socioeconômico gera mudanças nos padrões valorativos da sociedade, e estabelecem uma distinção entre valores de sobrevivência e valores de autoexpressão. $\mathrm{O}$ argumento é de que nas sociedades onde há o predomínio de valores de sobrevivência, ou seja, onde as questões materiais não estão resolvidas (emprego, renda, habitação, alimentação, transporte,...), encontra-se a democracia formal, mas não a democracia efetiva, ainda longe de se tornar real. Ao passo que as sociedades que alcançaram os 
valores de autoexpressão, ligados aos valores pós-materialistas, fruto dos processos de industrialização e modernização econômica, estão mais próximas da democracia efetiva, situação em que os direitos civis e políticos, previstos em lei, se tornaram efetivos na prática real.

$\mathrm{Na}$ mesma linha de argumentação, Baquero (2007) pondera que é indispensável levar em consideração, além da dimensão político-normativa, as dimensões econômicas, sociais e culturais para avaliar a qualidade democrática de um país. Propõe um modelo compreensivo da qualidade da democracia, conforme mostra a Figura 1.

Figura 1: Modelo Compreensivo da Qualidade da Democracia

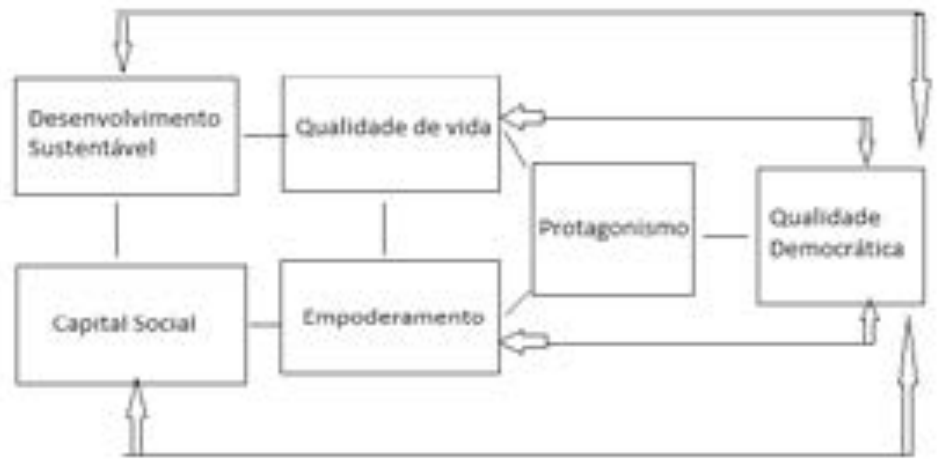

Fonte: Modelo elaborado por Macello Baquero, 2007.

De acordo com Baquero (2007), as dimensões para o alcance da qualidade da democracia estão interligadas, de modo que quanto maior a confiança social e o engajamento cívico, maior a probabilidade de haver comportamentos críticos e sustentáveis, e que por sua vez propiciará maior sustentabilidade ambiental e qualidade de vida. Neste círculo virtuoso, a democracia obterá maior grau de qualidade com o protagonismo e o empoderamento dos cidadãos.

Sustentabilidade expressa o uso responsável dos recursos naturais. Está ligada à preservação da natureza, à sobrevivência de todas as espécies vivas no planeta e à qualidade de vida humana. A lógica do crescimento econômico das sociedades contemporâneas (uso ótimo dos recursos) nem sempre respeita a lógica da sustentabilidade socioe- 
conômica (uso sustentável dos recursos). Há um amplo debate sobre as reais possibilidades do alcance do desenvolvimento sustentável e da segurança alimentar no século XXI, frente aos desafios da preservação e dos respeito aos recursos naturais não renováveis (Veiga, 2005).

Recente pesquisa corrobora com esta perspectiva a respeito da relação entre qualidade democrática e qualidade ambiental. Rodrigues et all (2015) utilizaram o Democracy Index que dimensiona a qualidade democrática dos regimes políticos e o Environmental Performance Index (EPI)3, que mensura o desempenho ambiental nos países. O EPI é composto por 22 indicadores que avaliam a saúde ambiental (impactos sobre a saúde, qualidade do ar, água e saneamento, recursos hídricos) e a vitalidade dos ecossistemas (biodiversidade e habitat, agricultura, florestas, pescas, clima e energia). Uma das constatações dos autores é de que os dados "evidenciam que a média de desempenho ambiental de países governados por democracias plenas é significativamente maior que a média de países governados por regimes autoritários no universo de países mais desiguais" (Rodrigues et all, 2015, p. 95).

Estas pesquisas elucidam que o debate acerca da distinção entre democracia formal e democracia efetiva não se dá apenas em função da institucionalização dos direitos civis e políticos, mas também na forma como os governantes têm respeitado estes direitos e como os cidadãos se comportam em relação à democracia. O Quadro 1 sintetiza as concepções de democracia e os seus respectivos indicadores de qualidade.

${ }^{3}$ Informações no site http://epi.yale.edu/epi/country-rankings - epi 2014 
Quadro 1: Democracia e indicadores de qualidade

\begin{tabular}{|c|c|c|}
\hline $\begin{array}{l}\text { Definição de } \\
\text { Democracia }\end{array}$ & Dimensões & Indicadores de qualidade \\
\hline $\begin{array}{l}\text { Minimalista: } \\
\text { Caracteriza-se pela } \\
\text { existência de procedi- } \\
\text { mentos que definem } \\
\text { quem está autorizado } \\
\text { a tomar as decisões } \\
\text { políticas. } \\
\text { Democracia Político } \\
\text {-eleitoral } \\
\text { (Bobbio; Dahl; Downs; } \\
\text { Sartori). }\end{array}$ & $\begin{array}{l}\text { Dimensões procedi- } \\
\text { mentais e processuais: } \\
\text { Primado da Lei } \\
\text { Participação } \\
\text { Competição } \\
\text { Direitos políticos } \\
\text { Liberdades civis. }\end{array}$ & $\begin{array}{l}\text { Estado de Direito/ direitos } \\
\text { políticos/ Participação elei- } \\
\text { toral/ Eleições livres, limpas } \\
\text { e periódicas/ Liberdade de } \\
\text { expressão, de imprensa, de } \\
\text { associação/ Fontes alternati- } \\
\text { vas de informação/ }\end{array}$ \\
\hline $\begin{array}{l}\text { Maximalista } \\
\text { Caracteriza-se pela } \\
\text { existência de procedi- } \\
\text { mentos eleitorais, e de } \\
\text { dimensões substan- } \\
\text { tivas que avaliam a } \\
\text { efetividade de direitos } \\
\text { e liberdades previstos } \\
\text { em lei. } \\
\\
\text { Democracia Efetiva / } \\
\text { Substantiva } \\
\text { (Baquero; Barreda;Moi- } \\
\text { sés; Munck; O'Don- } \\
\text { nell). }\end{array}$ & $\begin{array}{l}\text { Dimensões procedi- } \\
\text { mentais, processuais e } \\
\text { substantivas: } \\
\text { Primado da Lei } \\
\text { Participação } \\
\text { Competição } \\
\text { Liberdades políticas } \\
\text { Liberdades civis } \\
\text { Direitos políticos } \\
\text { Direitos sociais } \\
\text { Igualdade política } \\
\text { Igualdade social } \\
\text { Prestação de contas } \\
\text { Cultura Política }\end{array}$ & $\begin{array}{l}\text { Estado de Direito/ Soberania/ } \\
\text { Direitos políticos/ Participa- } \\
\text { ção eleitoral e participação } \\
\text { política ampliada/ Eleições } \\
\text { livres, limpas e periódicas/ } \\
\text { Liberdade de expressão, de } \\
\text { associação, de imprensa/ } \\
\text { Fontes alternativas de infor- } \\
\text { mação/Îndice de satisfação } \\
\text { com a democracia/ Indice de } \\
\text { Confiança nas instituições/ } \\
\text { Percepção da corrupção/ Me- } \\
\text { canismos de accountability } \\
\text { vertical, horizontal e social/ } \\
\text { Responsividade/ Capacidade } \\
\text { efetiva do governo. }\end{array}$ \\
\hline
\end{tabular}

Fonte: Elaboração própria a partir da literatura referenciada.

Observa-se que parte da literatura busca explicações institucionais e, portanto, enfatiza o desenvolvimento político e os aspectos procedimentais da análise da democracia, ao passo que outros autores buscam explicações socioeconômicas e culturais para compreender a durabilidade e a qualidade da democracia, especialmente no contexto latinoamericano. Na próxima seção serão abordadas a classificação dos países da América Latina e os principais indicadores da qualidade da democracia, tendo em vista compreender como as democracias são mensuradas em termos de sua qualidade. 


\section{QUALIDADE DA DEMOCRACIA NA AMÉRICA LATINA: OS PAÍSES DO MERCOSUL}

A questão da qualidade da democracia é complexa e controvertida, pois envolve uma gama de conceituações analíticas muito adversas. Contudo, o debate tende a ser profícuo na direção de um aprimoramento e consolidação dos princípios e da prática democrática, especialmente nos países latinoamericanos. Diversos pesquisadores têm se dedicado a estudar esse tema, mostrando uma real preocupação com as bases da legitimidade democrática e com a qualidade da democracia na região. Entre eles destacam-se Barreda (2012); Baquero (2012), Rennó et al (2011), Moisés (2010b).

A investigação da qualidade da democracia na América Latina tem se dado a partir da análise de dados e de estatísticas oficiais, bem como de dados de pesquisas de opinião, especialmente daqueles disponibilizados pela Corporação do Latinobarômetro ${ }^{4}$, pela ONG Transparência Internacional, pela Freedom House, entre outros. Apesar das críticas, uma das classificações internacionais mais utilizadas é a da Freedom House, que caracteriza 195 países com base na avaliação dos direitos políticos e das liberdades civis. A metodologia da pesquisa se baseia nos padrões básicos de direitos e liberdades afirmados na Declaração Universal dos Direitos Humanos. Um país é considerado "livre" quando alcança uma pontuação entre 1,0 a 2,5 pontos. Isso significa que neste país é observada a existência de competição política e respeito às liberdades civis, e uma mídia independente. Em um país "parcialmente livre", com pontuação entre 3,0 a 5,0 pontos, se observa que o respeito aos direitos políticos e às liberdades civis é limitado e parcial. O país classificado como "não livre" apresenta pontuação entre 5,5 a 7,0 pontos, e caracteriza-se pela ausência dos direitos políticos e pela negação das liberdades civis e políticas.

De acordo com o relatório disponibilizado pela Freedom House, os países na América Latina foram classificados da seguinte forma, conforme mostra a Quadro 2:

${ }^{4}$ A Corporação Latinobarômetro é uma ONG, com sede em Santiago do Chile, que realiza pesquisas anuais em 18 países da América Latina, desde os anos 1990, com amostras representativas de 1.200 entrevistados por país. 
Quadro 2: Classificação dos países latinoamericanos - Freedom House, 2013

\begin{tabular}{|c|c|c|c|}
\hline & Livres & Parcialmente Livres & Não Livres \\
\hline Países & Argentina/ Brasil/ Chile/ & Bolívia/ Colômbia/ Equador/ & Cuba \\
& $\begin{array}{c}\text { Costa Rica/ El Salvador/ } \\
\text { República Dominicana/ } \\
\text { Panamá/ Peru/ Uruguai. }\end{array}$ & $\begin{array}{c}\text { México/ Nicarágua/ Honduras/ } \\
\text { Venaraguai/ }\end{array}$ & \\
& & Venuela. & \\
\hline
\end{tabular}

Fonte: Freedom in the World 2013: Democratic Breakthroughs in the Balance.

Segundo a Freedom House, o Paraguai foi caracterizado como um país não livre em vários momentos de sua história política, muito em função dos golpes de Estado no país. Mas, desde os anos 1990 tem sido classificado como parcialmente livre. O que chama a atenção nestes países é que, a despeito da existência de eleições, são flagrantes as violações aos direitos e liberdades civis, a censura aos meios de comunicação, a arbitrária violência policial, e a falta de alternância política entre os partidos políticos. Trata-se, portanto, de democracias com características híbridas, pois a normatividade institucional tem convivido com uma cultura política conservadora e autoritária, com precário apoio específico e substantivo (Moisés, 2010b; Baquero, 2012).

Para os propósitos deste artigo, serão analisados os países do Mercado Comum do Sul (Mercosul): Argentina, Brasil, Paraguai, Uruguai e Venezuela, tendo em vista sua integração econômica e os seus aspectos comuns no tocante aos indicadores democráticos, econômicos e sociais, bem como avaliar seus desafios particulares. A escolha do período de 2010 a 2013 deve-se à existência de dados completos referente às variáveis selecionadas, para os cinco países estudados.

Para avaliar a qualidade da democracia entre os países, foi escolhido o índice proposto pela "Democracy Ranking Association", que publica anualmente o ranking das democracias contemporâneas, a partir da avaliação de variáveis políticas: direitos políticos, liberdades civis, liberdade de imprensa, índice de corrupção, alternância de partido político no governo; e de variáveis não-políticas, como indicadores econômicos, igualdade de gênero, grau de conhecimento, condições da saúde e do meio ambiente. A fórmula conceitual do ranking tem como base as reflexões teóricas de Guillermo O'Donnell sobre a qualidade da democracia, que agrega direitos humanos e 
desenvolvimento sócio-econômico e político (Quality of Democracy $=($ freedom + other characteristics of the political system $)+($ performance of the non-political dimensions).

Utiliza-se também o Índice de Percepções da Corrupção (IPC), um indicador composto, utilizado para medir a percepção da corrupção no setor público em diferentes países do mundo. A metodologia inclui a seleção de fontes de dados confiáveis e a padronização e ajuste de cada uma das fontes de dados para torná-los compatíveis. A escala é de 0 a 100, onde 0 é o nível mais alto de corrupção percebida, e 100 o menor nível de percepção da corrupção. No âmbito dos indicadores econômicos foram utilizados o índice de Gini, a taxa de pobreza (pessoas que vivem com até US\$ 4,00 por dia) e a taxa de crescimento anual do Produto Interno Bruto (PIB) por habitante, disponibilizados pela Comissão Econômica da América Latina (CEPAL) e pelo Socio-Economic Database for Latin America and the Caribbean (SEDLAC).

De acordo com os dados, as democracias na América Latina vivenciam momentos de estabilidade e instabilidade, ao longo dos últimos anos. Em perspectiva comparada, o Uruguai é um dos países do Mercosul mais democráticos, como mostra o Gráfico 1.

Gráfico 1: Qualidade democrática, indicadores econômicos e percepção da corrupção: Uruguai 2010-2013

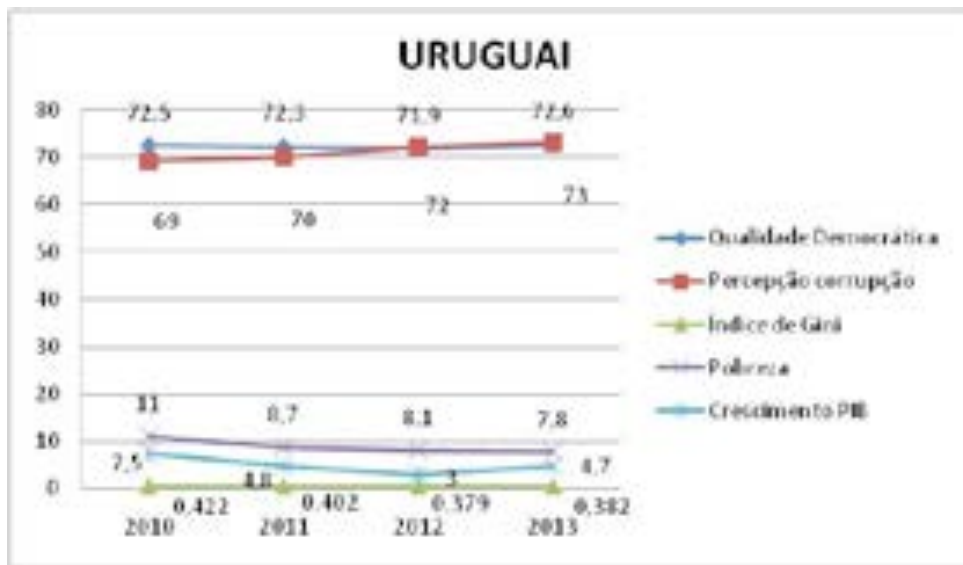

Fonte: Elaborado pela autora com base nos dados da Democracy Ranking Association, da Transparency International,da CEPAL e do SEDLAC. 
A democracia uruguaia se caracteriza pela existência de instituições políticas consolidadas e de valores democráticos mais sólidos na região. Tem um sistema partidário institucionalizado, com financiamento público desde 1928, por meio de leis ad hoc, votadas a cada eleição. Em relação aos valores democráticos, pesquisas mostram que há uma base normativa de apoio à democracia significativa por parte dos uruguaios ${ }^{5}$. A satisfação e o apoio dos cidadãos se devem a avanços protagonizados por governos pós-1985, como a exigência de transparência para a prestação de contas, o acesso a informações, o combate à corrupção através de leis rígidas, e a promoção do crescimento econômico associado ao bem-estar e a melhores condições de vida. O Uruguai apresenta os melhores indicadores de qualidade democrática, os níveis mais baixos de corrupção, de desigualdade e de redução da pobreza. Mas no tocante à taxa de crescimento do PIB, vem apresentando um declínio ao longo dos anos, o que pode ser explicado em parte pela crise econômica mundial. $\mathrm{O}$ presidente da República, Tabaré Vázquez, da Frente Ampla, assumiu a presidência do país em março de 2015, em seu terceiro mandato. De acordo com a literatura, o Uruguai alcançou um patamar de qualidade democrática em todas as suas dimensões: político-normativo, econômicas e sociais.

Com mais de 30 anos de regime democrático, a Argentina é o segundo país do bloco que apresenta melhores indicadores de qualidade democrática, mas do ponto de vista econômico se destaca entre os países com maior declive do crescimento do PIB, atingido por sucessivas crises econômicas, conforme aponta o Gráfico 2.

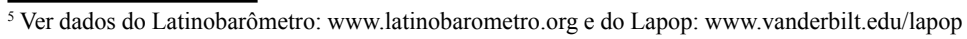


Gráfico 2: Qualidade democrática, indicadores econômicos e percepção da corrupção: Argentina 2010-2013

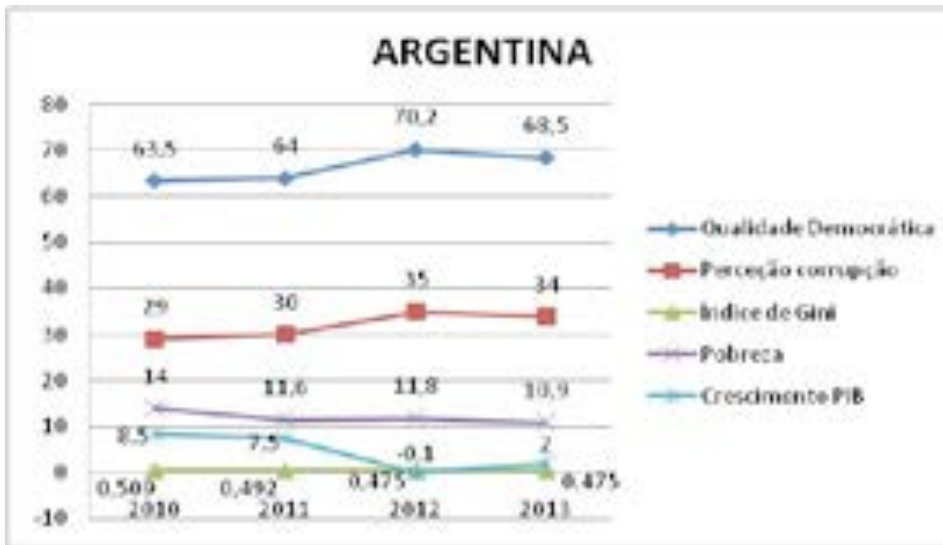

Fonte: Elaborado pela autora com base nos dados da Democracy Ranking Association, da Transparency International, da CEPAL e do SEDLAC.

Obs: Índice de Gini da Argentina é referente ao contexto urbano.

O país experimentou uma recuperação econômica, e investiu em programas sociais de transferência de renda (Asignación Universal por Hijo), o que contribuiu para a redução da pobreza. Ainda que os dados indiquem redução da pobreza e das desigualdades, economistas advertem de que a pobreza na Argentina pode ter se transformado em um fenômeno estrutural.

Com relação ao crescimento do PIB, observa-se um declínio entre os anos de 2012 e 2013, e no ranking de expectativa de crescimento para 2015, Argentina ocupa o $17^{\circ}$ lugar. Cristina Kirchner, presidente da República desde 2007, a despeito da crise econômica e de denúncias de corrupção no seu governo, mantém popularidade de $40 \%$. Parte-se da premissa de que quanto maior a qualidade da democracia, maior a transparência e menor a onda de corrupção na política. O que se observa nos dados da Argentina, é que há um aumento nos indicadores de qualidade democrática, ao mesmo tempo em que a percepção da corrupção diminui, embora existam vários casos de corrupção envolvendo integrantes do governo e empresários, enriquecimento ilícito e favoritismos, ao longo do período estudado.

Osvaldo Iazzetta (2010) ao abordar a democracia argentina, 
fala sobre a sobrevivência de práticas tradicionais, especialmente da plebiscitária, ao longo do processo de democratização. O autor argumenta que é preciso destacar que,

a continuidade da vida democrática conviveu com um processo acentuado de desigualdade social que priva muitos argentinos da base material necessária para assegurar a sua autonomia como cidadãos. A recuperação dos direitos políticos - eleger e ser eleitos coexiste com uma forte deterioração dos direitos sociais e civis que permitem assegurar uma vida digna e o acesso de todos à justiça (IAZZETTA, 2010, p. 124).

O referido autor argumenta ainda que os altos níveis de desigualdade social registrados fomentam questionamentos sobre o tipo de políticas públicas têm sido implementadas nos regimes democráticos da América Latina, nos últimos anos. De acordo com a literatura, a Argentina alcançou um patamar de democracia político-eleitoral, mas quanto aos resultados das políticas ainda não conquistou uma democracia mais efetiva e substantiva.

No caso do Brasil, um importante parceiro comercial dentro do Mercosul, as desigualdades também se mantém altas após a redemocratização. A democracia brasileira se caracteriza pela existência de eleições periódicas, livres e justas, marcadas por uma expressiva participação eleitoral e competição entre os partidos políticos. Estudos revelam que a decisão do voto tem sido pautada mais no personalismo político do que nos partidos políticos, que têm apresentado baixos níveis de confiança nas pesquisas de opinião (Baquero, 2012; Moisés, 2010b). Esse dado é preocupante do ponto de vista da cultura política, pois a base de apoio normativo e específico é fundamental para a sustentação das instituições políticas. De acordo com os dados do Gráfico 3, a democracia brasileira oscila num patamar mediano. 
Gráfico 3: Qualidade democrática, indicadores econômicos e percepção da corrupção: Brasil 2010-2013

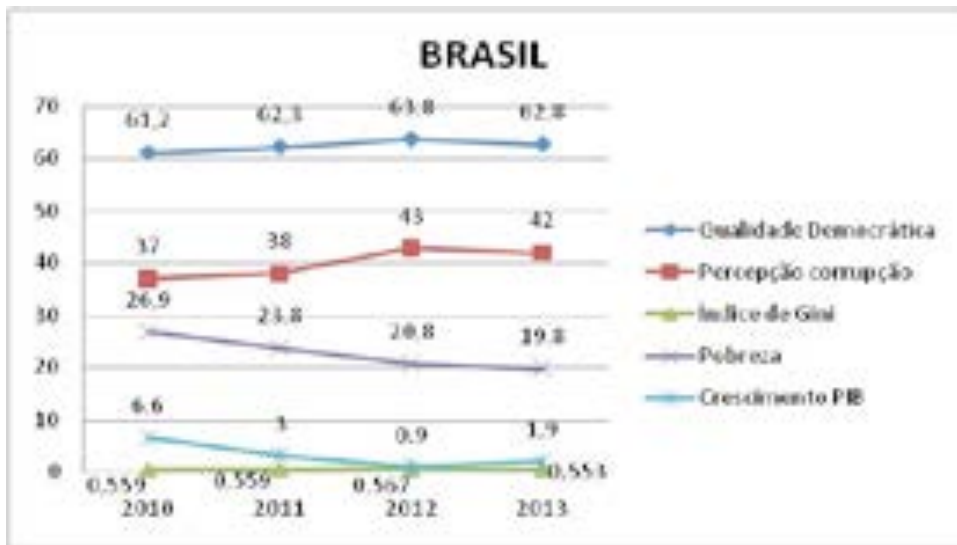

Fonte: Elaborado pela autora com base nos dados da Democracy Ranking Association, da Transparency International, da CEPAL e do SEDLAC.

Os pontos fortes da qualidade da democracia no Brasil estão concentrados nos fatores político-institucionais, e entre os pontos fracos estão a fragilidade dos mecanismos de prestação de contas e os inúmeros atos de corrupção na política. Nos últimos anos, as instituições de controle e fiscalização, como a Polícia Federal, o Ministério Público e os Tribunais de Contas, têm se empenhado nas denúncias, investigações e processos de punições aos corruptos, computando avanços para a qualidade da democracia.

Mas a corrupção tem sido um dos problemas mais sérios vivenciados pela democracia brasileira, pois ela envolve abuso do poder e desvios de recursos públicos. Apenas para citar dois casos mais recentes: 1) o do "Mensalão", esquema de compra de votos de parlamentares, que ocorreu no governo Lula da Silva, em 2005; e 2) a operação "Lava Jato", esquema de corrupção e lavagem de dinheiro, envolvendo a Petrobrás, empreiteiros e políticos, deflagrada em março de 2014, cuja investigação segue no período do governo Dilma Rousseff. O escândalo envolvendo a Petrobrás, maior empresa estatal de economia mista, gerou o rebaixamento da nota de crédito no mercado internacional, causando perda do seu grau de investimento. Pesquisas confirmam que os efeitos da corrupção afetam a qualidade da democracia, pois diminuem a adesão 
ao regime, estimulam a aceitação de escolhas autoritárias, influenciam negativamente a submissão à lei e a confiança interpessoal, e inibem tendências de participação política (Moisés, 2010a).

Houve avanços na área social, especialmente com os programas de transferência de renda, como o Bolsa Família, que contribuiu para a redução na taxa de pobreza. Mas ainda persistem altos níveis de desigualdade na distribuição de renda no país. Diante da crise política e econômica, ocorreram protestos e manifestações em todo o Brasil, onde milhares de cidadãos saíram às ruas exigindo punição aos envolvidos nos esquemas de corrupção e reivindicando maiores investimentos nas áreas da saúde e educação, de forma similar aos investimentos que estavam sendo feitos nas obras da Copa do Mundo (2014), que foi realizada no Brasil (Manifestações de Junho 2013). Esse fato endossa que a participação no Brasil é ampliada. As taxas do crescimento do PIB mostram-se em declínio, reflexo da grave crise econômica que tem sido agravada pela estagnação, recessão e alta inflação. Estudos da Organização para a Cooperação e Desenvolvimento Econômico (OCDE) indicam que a crise econômica brasileira tem sido acirrada pela crise política, ocasionando falta de credibilidade dos investidores internacionais ${ }^{6}$.

De acordo com a literatura, o Brasil alcançou um patamar de democracia político-institucional, com garantias constitucionais que asseguram direitos políticos, liberdades individuais, e igualdade política. Entretanto, ainda está longe de atingir um nível mais alto de qualidade democrática devido à avaliação mais substantiva dos fatores políticos (práticas antidemocráticas), econômicos e sociais (pobreza e desigualdades), e culturais (existência de uma cultura política híbrida).

Dentre os países da América Latina, o Paraguai é um dos menores em extensão territorial e populacional, e como membro do Mercosul, ocupa uma posição marginal e dependente do comércio e dos investimentos dos países vizinhos, particularmente pela necessidade de uso dos portos do Brasil e Argentina para o escoamento de sua produção. Apresenta baixo grau de qualidade democrática e alta percepção da corrupção, como se observa no Gráfico 4, a seguir.

6 Informações no site http://www.oecd.org/brazil 
Gráfico 4: Qualidade democrática, indicadores econômicos e percepção da corrupção: Paraguai 2010-2013

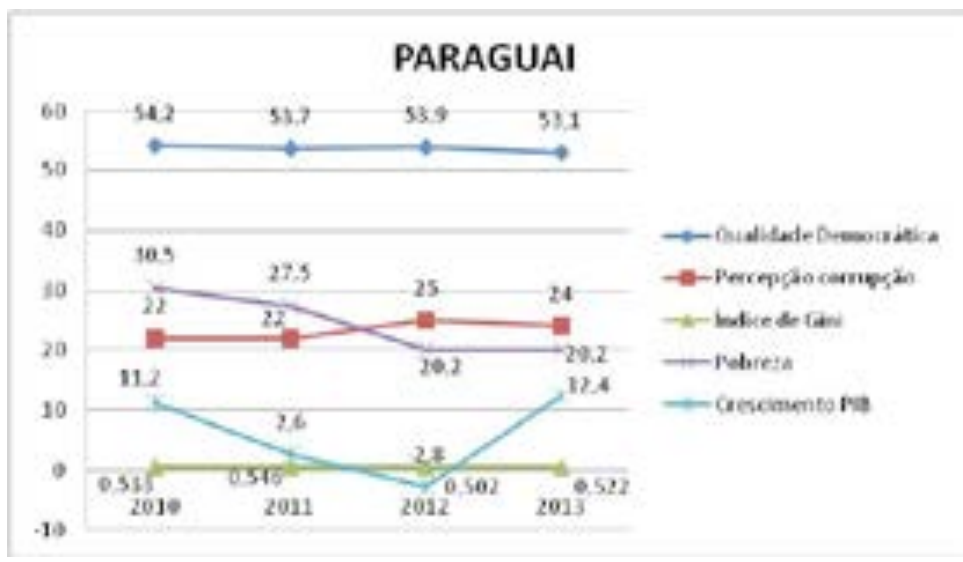

Fonte: Elaborado pela autora com base nos dados da Democracy Ranking Association, da Transparency International, da CEPAL e do SEDLAC.

O cenário político da democracia no Paraguai permanece instável, apesar da crescente pluralização obtida com a emergência de novos atores políticos e sociais em 2008. Entretanto, há uma convivência de valores democráticos com práticas tradicionais e conservadoras, configurando uma cultura política híbrida no país. O Paraguai sofre com a herança deixada pelo stronismo na esfera política e social, dentro de um quadro de elevada exclusão social e pobreza, enriquecimento ilícito de uma minoria, corrupção e exercício autoritário do poder. Por isso, um dos grandes desafios da democracia paraguaia é superar as desigualdades sociais e os vícios do regime autoritário, que mantém uma estrutura administrativa centralizada, pouco eficiente e que reforça a cultura da informalidade e do clientelismo (Amorim, 2010).

A avaliação negativa que os cidadãos paraguaios têm feito nos últimos anos em relação ao desempenho socioeconômico do regime democrático deve-se, principalmente, ao aumento da pobreza e das desigualdades sociais e às crescentes denúncias de corrupção na política. A experiência autoritária e ditatorial vivida pelo Paraguai marca até hoje as ações do Estado democrático e a conseqüente avaliação negativa dos cidadãos .

7 Informações no site www.latinobarometro.org 
De acordo com os dados do Gráfico 4, se observa uma recuperação do crescimento do PIB em 2013, explicada pelo desenvolvimento positivo dos setores da construção, da pecuária e da indústria. O crescimento deve-se também a uma maior diversificação das exportações no Paraguai. As taxas de pobreza se reduziram, no período estudado, em função de programas sociais, como o Programa de Transferência Condicionada Tekoporã. Contudo, persistem desigualdades em todas as áreas, e acesso limitado a serviços básicos, especialmente nas áreas urbanas do país, revelando que o crescimento econômico, em si, não é sinônimo de justa distribuição de renda e de melhoria da qualidade democrática. De acordo com a literatura, o Paraguai alcançou um patamar de democracia eleitoral, mas com sérios problemas de cunho institucional, especialmente frente a denúncias de fraudes nas eleições presidenciais. O sistema de partidos paraguaio sempre se caracterizou pelo bipartidarismo com partido hegemônico, onde o Partido Colorado sempre triunfou nas disputas eleitorais, mantendo-se no poder por 60 anos. Configurou-se, dessa forma, um Estado patrimonialista, pautado na tríade de poder composta pelo Estado, Forças Armadas e Partido Colorado.

A Venezuela apresenta alguns aspectos peculiares em relação aos países do Mercosul. Ao mesmo tempo em que pesquisas indicam baixos indicadores de qualidade democrática e dificuldades econômicas, nos últimos anos o país apresentou a terceira maior média de apoio e satisfação com a democracia ${ }^{8}$. A popularidade do ex-presidente Hugo Chávez, que governou a Venezuela entre 1999 a 2012, se manteve alta em todo o período estudado. Como dito anteriormente, a tendência ao personalismo político é bastante presente na América Latina, e o chavismo se configurou como um apelo à refundação do Estado, numa proposta de "democracia revolucionária e socialista" baseada no poder popular (SILVA, 2012). A seguir, o Gráfico 5 mostra os indicadores da qualidade da democracia, os níveis de percepção da corrupção e os indicadores econômicos do país.

8 Informações no site www.latinobarometro.org 
Gráfico 5: Qualidade democrática, indicadores econômicos e percepção da corrupção: Venezuela 2010-2013

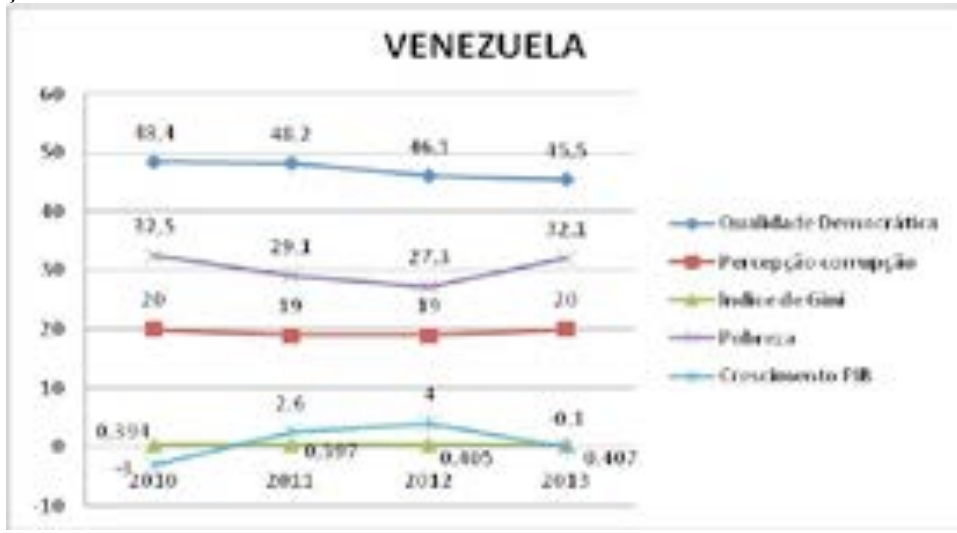

Fonte: Elaborado pela autora com base nos dados da Democracy Ranking Association, da Transparency International, da CEPAL e do SEDLAC.

Com relação às variáveis políticas ponderadas pela Democracy Ranking Association, a democracia venezuelana realiza eleições periódicas e livres, dentro de uma dinâmica partidária. Mas no intuito de instaurar novas instituições, Hugo Chavez instituiu conselhos comunais, organizados em células locais com financiamento do poder central, de modo a promover a participação direta da população. A despeito do funcionamento institucional, há uma preocupação com a atuação do poder judiciário, considerado pouco autônomo, ineficiente e partidarizado. Existem denúncias de que os magistrados, que não acessaram o cargo através de concurso público, sofrem pressão ao tomar decisões contrárias ao governo (Peterlevitz, 2011). Além desses fatores, a Venezuela também recebeu baixa pontuação na qualidade democrática nos seguintes quesitos: liberdades civis (liberdade de imprensa e de expressão), índice de corrupção e alternância de partido político no governo. Há muita polêmica em torno das restrições à liberdade de imprensa e ao direito à manifestação na Venezuela. Recentemente, um líder da oposição foi condenado a 14 anos de prisão, acusado de ter incitado protestos contra o governo, que resultaram na morte de 40 pessoas. 
Segundo a Transparência Internacional, a Venezuela é um dos países da América Latina que apresenta os maiores índices de corrupção na política. Há registros de casos de corrupção nos altos escalões do governo e ocorrências no âmbito do funcionalismo público. A empresa petroleira estatal (PDVSA) está sendo investigada pelo envolvimento em escândalos de corrupção, o que afeta negativamente $o$ crescimento econômico devido a perda de credibilidade nos mercados internacionais. A produção e a exportação do petróleo constituem a base propulsora da economia venezuelana, e as oscilações dos preços do petróleo somados aos casos de corrupção, aumentam a vulnerabilidade do país. Conforme observado no Gráfico 5, as taxas de pobreza e o índice de Gini apresentam um gradativo aumento ao longo do período estudado, expressão da crise política e econômica do país.

De acordo com a literatura, a democracia na Venezuela está longe de ser efetiva por apresentar baixos indicadores de qualidade democrática, associados à alta percepção da corrupção e índices socioeconômicos negativos. A proposta de instaurar um poder popular revela-se incoerente com as restrições impostas à liberdade de expressão e de opinião, através de leis aprovadas no parlamento, que restringem a navegação na internet, impõem limitações nos conteúdos de rádio e de televisão e permitem que o governo cancele licenças de transmissão sem justa causa, conforme aponta a organização Human Rights Watch. A garantia da liberdade de expressão, através de uma mídia independente e fontes diversificadas de informações são algumas das exigências mínimas para um regime democrático.

\section{CONSIDERAÇÕES FINAIS}

$\mathrm{Na}$ América Latina, de acordo com os critérios internacionais estabelecidos, apenas Cuba e Haiti não respondem positivamente às características de um país democrático. Os demais dezoito países compartilham dos aspectos procedimentais e processuais mínimos de uma democracia político-eleitoral. De acordo com os índices de qualidade da democracia, apontada pelos mais diversos estudos, Uruguai, Chile e Costa Rica são os países considerados mais de- 
mocráticos da região, contudo, os demais países apresentam baixas pontuações de qualidade da democracia, além de baixos indicadores socioeconômicos. Essa avaliação negativa se deve à existência de limitações dos direitos políticos e liberdades civis, altos índices de corrupção na política, e baixos níveis de confiança, de apoio e de satisfação dos cidadãos com o regime democrático.

A corrupção, a pobreza e a desigualdade estão entre as principais preocupações quando se trata de avaliar a qualidade da democracia no contexto da América Latina. Nas sociedades pós-industriais, a questão material está resolvida, e o debate democrático gira em torno de valores pós-materialistas. Entretanto, em países em desenvolvimento, como os latinoamericanos, a segurança alimentar, o bem-estar material, a segurança física, a qualidade de vida, a qualidade ambiental, são variáveis fundamentais para o alcance de indicadores mais altos de qualidade democrática.

Uma democracia de qualidade, sinônimo de uma democracia efetiva, prevê a garantia dos direitos políticos, não apenas através da participação eleitoral, mas em diversas instâncias formais e informais da política, como organizações partidárias, associações, manifestações públicas, protestos... Pressupõe uma participação política que influencie, de fato, o processo político e decisório. Por outro lado, a corrupção, ao invés de ser naturalizada, revela-se uma das infrações mais graves da democracia efetiva, pois denota que os líderes políticos estão desrespeitando a lei e comprometendo a gestão pública. Numa perspectiva mais ampliada, a qualidade democrática também passa a ser avaliada pela capacidade de resposta dos governantes às demandas sociais, de modo a diminuir as desigualdades socioeconômicas, e garantir uma cidadania ativa, propositiva e crítica em relação à democracia real e substantiva.

Problematizar as definições de democracia e as suas implicações para a mensuração da qualidade da democracia, particularmente no contexto dos países latinoamericanos, é um empenho importante que contribui para os cidadãos e os governos repensarem suas práticas políticas. 


\section{REFERÊNCIAS}

AMORIM, M. S. S. Democracia e confiança política no Paraguai. Paper apresentado no $7^{\circ}$ Encontro Nacional da Associação Brasileira de Ciência Política-ABCP, Recife, Pernambuco, 04 a 07 de agosto, 2010. . Indicadores e parâmetros da qualidade da democracia. Paper apresentado no $I V^{o}$ Encontro Internacional de Ciências Sociais (EICS), Pelotas/RS - 18 a 21 de novembro de 2014.

BAQUERO, M. Democracia e Desigualdades na América Latina. Novas Perspectivas. Porto Alegre: Ed. UFRGS, 2007.

Avaliando o potencial de fatores culturais na construção da democracia na América Latina: uma comparação entre 2005 e 2010. Revista Debates (UFRGS), Vol. 6, pp. 9-34, 2012.

BARREDA, M. La calidad de las democracias latinoamericanas: medicion y claves explicativas. In: MUNCK, G.; MANTILLA, S. La calidad de la democracia: perspectivas desde América Latina. Quito, Ecuador, 2012. Disponível em http://www.hss.de/fileadmin/ americalatina/Ecuador/downloads/Version_1__Libro_Calidad_ de_la_democracia_1.pdf

BOBBIO, N. Teoria Geral da Política. A filosofia e as lições dos clássicos. Elsevier/Campus, RJ, 2000.

DAHL, R. Poliarquia: Participação e Oposição. São Paulo, Edusp, 1997.

DIAMOND, L.; MORLINO, L. The quality of democracy. In: Center on Democracy, Development, and The Rule of Law Stanford Institute on International Studies - CDDRL Working Papers - Number 20, 21 September 2004. Disponível em http://cddrl.stanford.edu/

DOWNS, A. Uma teoria econômica da democracia. São Paulo: Edusp, 1999.

FREEDOM IN THE WORLD 2013: Democratic Breakthroughs in the Balance. Selected data from Freedom House's annual survey of political rights and civil liberties. Disponível in: www. freedomhouse.org

HELD, D. Modelos de Democracia. Belo Horizonte, MG: Ed. Paidéia, 1987.

IAZZETTA, O. Luzes e sombras da democracia na Argentina: conquistas e temas pendentes. In: FAUSTO, Sérgio (Org.). Dificil democracia. 
São Paulo: Paz e Terra, 2010.

INGLEHART, R.; WELZEL, C. Modernização, Mudança Cultural e Democracia: a sequência do desenvolvimento humano. São Paulo: Ed. Francis, 2009.

LEVINE, D.; MOLINA, J. E. Calidad de la democracia: Fortalezas y Debilidades en América Latina. In: MUNCK, G.; MANTILLA, S. La calidad de la democracia: perspectivas desde América Latina. Quito, Ecuador, 2012. Disponível em http:// http://www.hss.de/ fileadmin/americalatina/Ecuador/downloads/Version_1__Libro_ Calidad_de_la_democracia_1.pdf

MOISÉS, J. Á. A corrupção afeta a qualidade da democracia? Em Debate, Belo Horizonte, Vol.2, nº.5, pp.27-37, 2010a.

Cultura política, instituições e democracia: lições da experiência brasileira. MOISÉS, J. A. (Org.). Democracia e Confiança. Por que os cidadãos desconfiam das instituições públicas? São Paulo: Edusp, 2010b.

MORLINO, L. Teoria da Democratização, Qualidade da Democracia e Pesquisa de Opinião: ainda em "mesas separadas”? In: MOISES, J. A. (Org.). Democracia e Confiança: por que os cidadãos desconfiam das instituições públicas? São Paulo: Editora da USP, 2010.

MUNCK, G. Conceptualizing the Quality of Democracy: The Framing of a New Agenda for Comparative Politics. In: MUNCK, G.; MANTILLA, S. La calidad de la democracia: perspectivas desde América Latina. Quito, Ecuador, 2012. Disponível em http://www. hss.de/fileadmin/americalatina/Ecuador/downloads/Version_1 Libro_Calidad_de_la_democracia_1.pdf

O’DONNELL, G. Democracia, desenvolvimento humano e direitos humanos. Revista Debates, Porto Alegre, Vol.7, nº.1, pp.15-114, 2013. Dossiê Qualidade da Democracia. Disponível em: http://seer. ufrgs.br/debates/article/download/36892/24040.

. Accountability horizontal e novas poliarquias. Lua Nova, $\mathrm{n}^{\mathrm{o}} .44$, pp. 27-54, 1998.

PETERLEVITZ, T. Conceituando e medindo a democracia em Colômbia e Venezuela. Dissertação (Mestrado em Ciência Política), FFLCH/ USP, 187 f., São Paulo, 2011.

PUTNAM. R. Comunidade e Democracia: a experiência da Itália moderna. 
Rio de Janeiro: Ed. FGV, 2002.

RENNÓ, L. et al. Legitimidade e qualidade da democracia no Brasil: uma visão da cidadania. São Paulo, Intermeios; Nashiville, LAPOP, 2011.

RODRIGUES, D. F. et al. A sustentável leveza da democracia? Os efeitos da qualidade democrática sobre o desempenho ambiental. In: Desenvolv. Meio Ambiente, Vol. 33, pp.81-99, abr. 2015.

SARTORI, G. A teoria da democracia revisitada. As questões contemporâneas. Vol. 1. São Paulo: Ed. Ática, 1994.

SCHUMPETER, J. Capitalismo, socialismo e democracia. Rio de Janeiro: Zahar, 1984.

SILVA, F. P. Democracia(s) em debate: novos discursos democráticos nos países andinos. In: OLIVEIRA, RP.; NOGUEIRA, SG.; MELO, FR. (Orgs). América Andina: integração regional, segurança e outros olhares [online]. Campina Grande: EDUEPB, 2012. pp. 255274. Available from SciELO Books.

VEIGA, J. E. Desenvolvimento Sustentável: o desafio do século XXI. Rio de Janeiro: Garamond, 2005.

\section{Relatórios e dados obtidos na internet:}

DEMOCRACY RANKING ASSOCIATION: www.democracyranking.org

TRANSPARENCY INTERNACIONAL: www.transparency.org

COMISSÃO ECONÔMICA PARA A AMÉRICA LATINA: www.cepal.org SOCIO-ECONOMIC DATABASE FOR LATIN AMERICA AND THE CARIBBEAN: http://sedlac.econo.unlp.edu.ar/eng/statistics.php

CORPORAÇÃO LATINOBARÔMETRO: www.latinobarometro.org

LATIN AMERICA PUBLIC OPINION PROJECT (LAPOP): www. vanderbilt.edu/lapop

ORGANIZAÇÃO PARA A COOPERAÇÃO E DESENVOLVIMENTO ECONÔMICO: http://www.oecd.org/brazil

Recebido: 30/08/2015.

Aprovado: 17/10/2015. 